\title{
As periferias digitais: mobilização para além da resistência ${ }^{1}$
}

\author{
Marco Antonio Bin \\ Doutor em Ciências Sociais pela PUC-SP; professor no curso de Comunicação Social \\ da FIAM-FAAM Centro Universitário e integrantes do Grupo de Pesquisa em Memória, \\ Comunicação e Consumo (MNEMON) do PPGCOM da ESPM. \\ E-mail: marcobin@gmail.com
}

Resumo: Tendo como referência as periferias urbanas, torna-se importante averiguar os avanços dos processos comunicacionais, naquilo que Henry Jenkins cunhou como cultura participativa, descrevendo a produção cultural e as interações sociais comunitárias, e, assim, identificar a vontade própria de experiência dos jovens como sujeitos empíricos. Ao recuperar os sentidos da segregação urbana que definem a desigualdade social e econômica na região metropolitana de São Paulo, o texto propõe discutir a realidade das periferias a partir da incorporação da tecnologia digital. Para além das transformações nos comportamentos cotidianos, as distintas plataformas de comunicação mobilizam a produção de conteúdo dos sujeitos de discurso, ao tempo que inscrevem na comunidade práticas culturais e demandas políticas em sintonia com os processos de consumo simbólico e material da contemporaneidade.

Palavras-chave: periferias; mobilização social; informação; redes digitais; São Paulo.
Abstract: Taking the urban peripheries as reference, is important to notice communicational processes' progress - in what Henry Jerkins calls participatory culture - describing cultural production and social interaction in the community and, therefore, to identify the young people's own desire for experience as empirical subjects. In recovering the meanings of urban segregation that defines social and economic inequality in the metropolitan region of São Paulo, the article proposes to discuss the reality of the peripheries under the communicational and creative aspect of themselves, from the incorporation of digital technology. In addition to the transformations in daily behavior, the different communication platforms mobilize the content production of the subjects of discourse, while inscribing in the community cultural practices and political demands in tune with the processes of symbolic and material consumption of contemporaneity.

Keywords: peripheries; Social mobilization; information; Digital networks; Sao Paulo.

\section{SÃO PAULO, CRESCIMENTO E SEGREGAÇÃO}

O posicionamento estratégico de São Paulo como centro financeiro, em razão da cultura do café que se esparramava por todo o oeste do estado, e próximo a o porto de Santos, que oferecia a imediata exportação do produto, permitiu que a cidade crescesse de modo vertiginoso, e de uma pequena 
2. Incluindo-se aqui a presença de sírios-libaneses e japoneses.

3. De acordo com o prof. Kabengele Munanga, ao citar Nina Rodrigues, "a imigração estrangeira para o Brasil (diz respeito) ao projeto de hegemonia do Brasil branco em relação ao eventual Brasil negro e mestiço. (Nina Rodrigues) associa a estagnação, o atraso de certas áreas, à alta concentração de sua população negra e mestiça: o progresso, a modernização da área meridional do país (está associada) à predominância da população branca. (MUNANGA, Kabengele. Negros e mestiços na obra de Nina Rodrigues. In: ALMEIDA, Adroaldo; SANTOS, Lyndon; FERRETTI, Sergio. Religião, Raça e Identidade. São Paulo: Ed. Paulinas, 2009, pp. $15-35$, p. 31.)

4. CALDEIRA, Teresa. Cidade de Muros - Crime, segregação e cidadania em São Paulo. São Paulo: Editora 34/Edusp, 2000.

5. HOLSTON, James. Cidadania Insurgente Disjunções da democracia e da modernidade no Brasil. São Paulo: Cia das Letras, 2013, p. 199.

6. VILLAÇA, Flávio. Espaço Intraurbano no Brasil. São Paulo: Estúdio Nobel/Fapesp, 2001, p. 329. cidade com cerca de 30 mil habitantes em 1870, passou a mais de 230 mil em 1900 e a 579 mil habitantes em 1920. Todo esse crescimento foi impulsionado pela forte chegada de um grande contingente de imigrantes europeus, principalmente italianos. Para se ter uma ideia dessa presença, na virada do século aproximadamente a metade da população da cidade era constituída de estrangeiros $^{2}$. O forte processo de imigração nesse período ocorreu em razão da política governamental que incentivou a importação de trabalhadores brancos europeus para substituir a mão de obra negra, em um procedimento de fundo étnico, que visava, sobretudo, ao "branqueamento" da população brasileira ${ }^{3}$.

Nesse período, São Paulo era uma cidade concentrada e aproximadamente $80 \%$ das moradias eram alugadas ${ }^{4}$. A elite que se origina da riqueza do café e do comércio dinâmico, logo busca se afastar do ambiente de promiscuidade e doenças ao se deslocar para áreas mais afastadas, em exclusivos empreendimentos imobiliários como o bairro de Higienópolis, assim nomeado em clara alusão às suas melhores condições de higiene.

O período subsequente, entre 1930 e 1980, registra a formação dos primeiros assentamentos populares em regiões mais distantes, as primeiras periferias da cidade. Conforme James Holston" ${ }^{5}$, aqui o conceito de periferia "refere-se a relações de dependência mútua - a produções sociais do espaço — nas quais as partes componentes definem umas às outras por meio de mecanismos de dominação e resposta”. Aprofunda-se com o passar dos anos a segregação residencial, que se intensifica com a chegada dos migrantes nordestinos nos anos 1950, que "foram forçados a construir seus lares em periferias mais distantes, definindo um processo de segregação espacial centrífugo e de diferenciação da cidadania (op. cit., p. 208)".

Para Flávio Villaça, o processo de segregação em São Paulo se dará em torno do que ele denomina de "quadrante sudoeste", ou em outras palavras, a centralidade original da cidade, definida pelo sítio original na região da Sé, sofre um deslocamento espacial no sentido sudoeste, alcançando a região da avenida Paulista e mais recentemente a região da avenida Luís Berrini. Trata-se de uma expansão definida pelos interesses históricos da classe média e pelo capital imobiliário, proporcionando uma área de segregação que atrai os equipamentos urbanos e estabelecem uma dominação sobre o espaço intraurbano como um todo. Segundo Villaça ${ }^{6}$,

[...] Assim, a luta de classes pelo domínio das condições de deslocamento espacial consiste na força determinante da estruturação do espaço intraurbano. Nem sempre as burguesias procuram o "perto" em termos de tempo e distância. Às vezes elas se afastam na busca de grandes lotes e ar puro, por exemplo, mas mesmo quando isso ocorre há limites para esse afastamento. Nesses casos, elas procuram trazer para perto de si seu comércio, seus serviços e o centro que reúne os equipamentos de comando da sociedade - e isso não por razões simbólicas ou de status, mas pela razão muito prática de que elas o frequentam intensamente e nele exercem muitos de seus empregos. 
O padrão de urbanização se modifica, a cidade se dispersa, as classes sociais passam a viver longe uma das outras: os pobres migram para as periferias; a classe média e alta ocupam os bairros centrais, mais equipados, em um processo de segregação social que se acentua ao longo das cinco décadas seguintes. O sistema de transportes também se modifica, cada vez mais os bondes desaparecerão, o ônibus chegará a espaços mais distantes, muitas vezes vazios, para atender aos crescentes fluxos de trabalhadores pobres, e o automóvel circunscreve-se aos ricos.

A cidade se verticaliza com a exploração imobiliária e a partir dos anos 1960, a classe média passa a ocupar apartamentos recém-construídos e financiados pelo $\mathrm{SFH}^{7}$, aprofundando o padrão de segregação urbana. Nos anos 1970, para Teresa Caldeira ${ }^{8}$, temos o seguinte panorama urbano:

Os pobres viviam na periferia, em bairros precários e em casas autoconstruídas; as classes média e alta viviam em bairros bem equipados e centrais, uma porção significativa delas em prédios de apartamentos. O sonho da elite da Velha República ${ }^{9}$ fora realizado: a maioria era proprietária de casa própria e os pobres estavam fora do seu caminho.

Os pobres, esquecidos e empurrados para as periferias cada vez mais distantes, se mobilizam com a abertura política (1979) para retomar as mobilizações por direitos civis e moradias, embora as dificuldades para o financiamento da casa própria persistam ${ }^{10}$. A autoconstrução torna-se dispendiosa ao longo dos anos 1980, e embora em ritmo menor que no período 1950-1970, ela prosseguirá, sobretudo nos extremos da cidade, onde o preço do lote de terra é mais barato e o controle público menos rigoroso (Kowarick, 2009). As dificuldades econômicas do período, que culminam com a grave crise financeira mundial de 1982 e a consequente declaração da moratória da dívida por parte do governo brasileiro, elevam o número de moradores das favelas na cidade e tal como a designação periferias, no plural, as favelas devem ser assim compreendidas, espaços diferenciados, múltiplos, ambientes com diferentes padrões sociais e distintos patamares de desigualdade, como diz Kowarick ${ }^{11}$,

As favelas e seus habitantes devem ser vistos no plural, pois não só são diferentes entre si, como, num mesmo aglomerado é frequente se encontrar padrões socioeconômicos e urbanísticos bastante diversos: elas constituem microcosmos que espelham os vários graus de desigualdade presentes nos estratos baixos de sedimentação da sociedade e, assim, não podem ser vistas como mundos à parte e excluídas da cidade em que estão inseridas.

Nos anos 1990, São Paulo é uma cidade mais complexa e fragmentada, mantendo a segregação, mas o modelo centro-periferia, marcado pelo distanciamento geográfico entre pobres e ricos, ainda que permaneça em seus contornos gerais, passa a ver o surgimento de empreendimentos imobiliários para as classes média e alta expandir para as áreas fronteiriças, avançando em espaços habitados por pessoas das classes menos favorecidas, criando espaços de moradia de luxo sob a designação de condomínios, ou, conforme Caldeira, enclaves fortificados.
7. Sistema Financeiro de Habitação, órgão federal que financiava a aquisição da casa própria.

8. CALDEIRA, Teresa, op. cit., p. 228.

9. Trata-se do primeiro período republicano, que vai da proclamação da República, em 1889, até a Revolução conduzida por Getúlio Vargas, em 1930.

10. Esta situação permanecerá até o Governo Lula (2003-2011), quando novas formas de crédito popular para a compra da casa própria estarão ao alcance das classes de baixa renda.

11. KOWARICK, Lucio. Viver em Risco - sobre a vulnerabilidade socioeconômica e civil. São Paulo: Editora 34/Edusp, 2009, pp. 224-225. 
12. Preconceito e xenofobia são sentimentos muito comuns encontrados nos bairros mais ricos, sempre em relação aos habitantes mais pobres, de origem nordestina. É importante lembrar que depois da chegada a São Paulo dos grandes contingentes migratórios europeus, no final do século XIX e princípios do século $X X$, nos anos 1940 e 1950 se deu início a uma grande onda migratória originária do Nordeste brasileiro, então a região menos desenvolvida do país, criando uma reação preconceituosa e xenófoba, onde no campo linguístico notabilizou-se a designação pejorativa "baianada" (referente ao estado nordestino da Bahia) para qualquer ação malfeita.

13. Conforme o Wikipédia, "em 2010, o seu Índice de Desenvolvimento Humano (IDH) era de 0,807 , considerando-se assim como elevado em relação ao país, sendo - $12^{\circ}$ maior do Estado". Localizadas do outro lado da rodovia Dutra, o Pinheirinho e o Campo dos Alemães eram geograficamente segregadas da área urbana principal da cidade.

14. FREIRE, Paulo. Ação Cultural para a Liberdade. Rio de Janeiro: Editora Paz e Terra, 1979, p. 49

15. Encontros de declamação literária.
É com esse panorama, centrado no crescimento de São Paulo ao longo do século XX, recuperando os sentidos de uma segregação urbana que marca a profunda desigualdade social e econômica paulistana ${ }^{12}$, que proponho a discussão sobre o padrão urbano de hoje, a realidade das periferias do ponto de vista delas, em um momento de mudança de hábitos definida pela utilização da tecnologia digital, onde novas e antigas organizações populares, definidas em coletivos e movimentos sociais, incorporam em sua mobilização processos comunicacionais que projetam suas vozes para além da comunidade, consolidadas em páginas de compartilhamento e de relacionamento criadas nas redes digitais - ferramentas preciosas na reelaboração de identidades e na produção das narrativas. A seguir, veremos como o acesso à portabilidade digital multiplicou a mobilização sócio-cultural-política nas periferias, e, como sugere o título deste artigo, estendendo-a para além da resistência posicional dos seus ideais.

\section{AS PERIFERIAS DIGITAIS E SUAS ARTICULAÇÕES CIDADÃS}

Há alguns anos, ao redigir um projeto acadêmico que pretendia justificar a instalação de polos culturais em uma área ocupada no interior de São Paulo, desenvolvi uma abordagem em relação aos objetivos a serem desenvolvidos em duas comunidades carentes, Pinheirinho, assentamento com cerca de 2 mil famílias, e o Campo dos Alemães. Tratava-se de uma população destituída de lazer e entretenimento, com mínima infraestrutura para uma vida social mais digna. Abandonada pelo poder público, desenvolvia-se em meio a mais completa precariedade, como fornecedora de mão de obra de baixa remuneração para a cidade de São José dos Campos ${ }^{13}$. Corrompidas pela alienação dos meios hegemônicos de comunicação, amaciadas em seus anseios mais vitais, as pessoas sobrevivem o dia a dia.

A proposta da implantação do polo cultural teve a aspiração de apoiar o desenvolvimento de práticas culturais que trouxessem o convívio comunitário como elemento de integração dos bairros precários, despertando seus moradores para atividades que os mobilizassem cultural e politicamente. E, no caso, especificamente, para o trabalho com a construção poética, a interação pela palavra, ou como diria Paulo Freire $^{14}$, a ação da palavra em linguagem e pensamento no mundo em que se vive - ou seja, a palavração. A poesia com o poder de confraternizar, de proporcionar o aprendizado bem como a consciência de se poder nomear o mundo, a partir da realização de saraus poéticos ${ }^{15}$.

As experiências de encontros culturais que conheci nas periferias paulistanas desenvolveram-se em bares, o espaço público por excelência (além dos templos religiosos) e a escolha do polo cultural no Pinheirinho ou no Campo dos Alemães poderia recair em uma escola pública, ampliando a força e o sentido simbólico deste espaço junto aos moradores. Para a iniciativa dar resultados, 
seria importante convocar os artistas da quebrada ${ }^{16}$, dar-lhes a visibilidade e a responsabilidade da ação social em curso.

A poesia declamada poderia encontrar na escola o ambiente natural para se reproduzir junto a outras práticas culturais, como grupos musicais, de teatro, de dança, encontros gastronômicos, festas tradicionais, atividades de cidadania que podem surgir no vácuo dos saraus, ou despontar de modo independente. A escola pública teria, assim, o papel de irradiar os valores culturais locais, disseminando entre os moradores a naturalidade do aprendizado, sempre produzindo jovens educadores que pudessem atuar na formação dentro das comunidades.

Embora tivesse o desejo de contribuir com a mobilização cultural dos assentamentos, a demora em desenvolver o processo juntamente com os moradores prevaleceu, retardando de modo definitivo a observação participante que levantasse, junto à comunidade, seus problemas e suas prioridades como aspectos decisivos para a elaboração de um projeto comum. Também não foi considerada a possibilidade então possível e realizável (2010) de desenvolver o projeto amparado na dinâmica das redes digitais. De algum modo, reproduzia a presunção derivada de uma antropologia já superada, onde o objeto a ser estudado estimulava o olhar e a análise hierarquizada, ainda que bem-intencionada. Uma antropologia cujo distanciamento cultural produzia uma etnografia que eliminava o desconforto do estranhamento, e, assim, qualquer identificação com o grupo social estudado.

$\mathrm{O}$ ato revelador do olhar multicultural me alcançaria no verdadeiro convívio com os grupos em questão, que, me absorvendo em sua realidade cotidiana, apresentaria todas as virtudes e deficiências nos relacionamentos humanos. $\mathrm{Ou}$ seja, uma aplicação da avaliação de Laplantine ${ }^{17}$ — de que somos uma cultura possível dentre tantas outras, mas não a única - análise que possibilita refletir sobre as tensões e equívocos de uma visão social de mundo. Com Viveiros ${ }^{18}$, o fazer antropologia nada mais é do que compará-las - as operações intelectuais entre o antropólogo e o nativo, por exemplo, nesse processo, revelam-se como exercício da tradução na prática etnográfica, que possibilita os conceitos alheios deformarem e subverterem os dispositivos conceituais do tradutor. Considero importante essa contribuição conceitual, pois a boa tradução, onde a interpretação resulta do comunicar pela diferença, assume um papel significativo na incorporação tecnológica na vida contemporânea. Ou seja, no caso das periferias urbanas, a comunicação necessariamente não presume silenciar o outro, mas torná-lo integrado pela participação interativa.

Assim, ao trazer o conceito de periferias digitais para este trabalho, o desejo é compreender as práticas sociais periféricas a partir das novas plataformas comunicacionais, verificando como a circulação e o compartilhamento de conteúdo midiático mobilizam as interações entre as pessoas ${ }^{19}$. A democratização ao acesso da informação e do conhecimento, com base na cultura de convergência, ofereceu novos ambientes de relações e propiciou um fluxo de mídia ilimitado, com a atuação proeminente, no caso das periferias, de criadores de conteúdos sociais locais, gerando sua propagabilidade pelas mais diversas plataformas
16. Quebrada: maneira de como os moradores das periferias se referem à comunidade em que vivem.

17. LAPLANTINE, François. Aprender Antropologia. São Paulo: Editora Brasiliense, 2012.

18. VIVEIROS, Eduardo. Equívocos da Identidade. In: GONDAR, Jo; DODEBEI, Vera. O que é Memória Social? Rio de Janeiro: Editora UFRJ, 2006, pp. 145-160.

19. JENKINS, Henry, Cultura da Conexão. São Paulo: Editora Aleph, 2014. 
20. Disponível em: <www. $\mathrm{mc}$. gov.br/publicacoes/ doc_download/2555pnad-tic-2013>, pp. 24-25 Acesso em: 01 nov. 2016.

21. MORDUCHOWICZ, Roxana. Los adolescentes y las redes sociales - la construcción de la identidade juvenil em Internet. Buenos Aires: Fondo de Cultura Económica, 2012, p. 23.

22. Destaco o cidadão da periferia, em especial o jovem morador das comunidades periféricas, por ser uma conquista relativamente recente, e também pelo tema deste artigo, que me leva a concentrar as análises ao universo de habitantes das periferias. digitais, contribuindo para a ruptura monopólica dos veículos oligopólicos de comunicação, cuja tradicional lógica discursiva sempre priorizou a construção verticalizada da linha editorial, restringindo o debate e a participação dos grupos sociais dos espaços de precariedade.

A título de ilustração, com respeito ao acesso à internet e posse de telefone celular móvel para uso pessoal, de acordo com os dados disponíveis no PNAD 2013 para a Região Metropolitana de São Paulo (RMSP), 92,9\% dos domicílios dispunham de acesso à telefonia móvel celular, sendo que 62,4\% possuíam microcomputador ligado à internet ${ }^{20}$. Ainda que os dados abarquem indistintamente territórios da RMSP com alta e baixa vulnerabilidade, é possível observar um considerável acesso à base digital, principalmente à telefonia celular. No caso dos jovens, conforme Morduchowicz ${ }^{21}$, as plataformas digitais e seus distintos aplicativos lhes "permite entender quem são, como se definem socialmente e como é e funciona a sociedade em que vivem", e, no caso do ativismo nas periferias, o protagonismo tecnológico se remete a uma interação social, com a promissora - e desejada - possibilidade de se romper com o círculo vicioso da informação oligopolizada, patronal. Também se rompe no processo a hegemonia do discurso, a hierarquia informacional substituída por uma comunicação horizontal, rica em suas experimentações, em suas conexões, onde a participação significa intervenção e cada vez mais livre, a partir dos espaços Wi-Fi e do acesso à portabilidade. As grandes estruturas corporativas midiáticas passaram a sofrer o assédio da escolha individual por outros canais de informação e conhecimento, e, o mais importante, o cidadão das periferias ${ }^{22}$ deixou, a partir dessa escolha, de ser um receptor inerme para se tornar um agente ativo na produção de conteúdo. E o mais importante, a experiência midiática passa a ser coletiva e contínua.

Assim, o controle da informação e do conhecimento - e do entretenimento até muito recentemente restrito ao aparelho de televisão nas comunidades carentes - passou a dar lugar ao fluxo de informações compartilhadas, permanentemente atualizadas. O esforço deste texto é abordar, ainda que sem a profundidade devida, os diversos aspectos que configuram a força da comunicação digital junto às comunidades periféricas, e graças ao seu acesso universal, como um eficiente instrumento para a consolidação da organização social local.

Hoje, sem prejuízo ao presencial, desponta a comunicação virtual digitalizada, que, ao contrário do que se poderia pensar, não se dilui, mas aproxima todos estes jovens e todos os sonhadores - termo preferível a empreendedores que, de seus lugares geográficos, não apenas convocam com apelo mais forte e abrangente para suas práticas culturais das quebradas, mas igualmente conseguem lançar sua voz e se comunicar para além das fronteiras periféricas. Está claro que estes benefícios digitais abrangem toda a sociedade sem distinção, mas para a população pobre das periferias urbanas, eles se tornaram uma poderosa conquista que reproduz não só identificação e resistência, mas o desfrute de uma gama imensa de ações, que vão das mais inusitadas inspirações para o imaginário individual, às mais complexas realizações de projetos coletivos. Numa 
palavra, nunca o indivíduo das periferias pobres pode almejar tão claramente em ser protagonista da construção da cidadania.

Trago, a seguir, breves descrições de ações de coletivos e movimentos sociais instalados nas periferias de São Paulo, que se exprimem para além dos horizontes da comunidade.

\section{O ESPAÇO DAS PERIFERIAS: PARTICIPAÇÃO E INTERAÇÃO}

Se na primeira parte deste artigo se destacou, de modo breve, o processo histórico de crescimento e de segregação urbana da cidade de São Paulo, e na segunda parte, avaliou-se as perspectivas da informação e do conhecimento apoiados na cultura da convergência, nesta seção gostaria de apresentar alguns espaços digitais que expressam a atuação de coletivos ancorados nas periferias, cujo trabalho social promove a participação da quebrada não só em termos de uma articulação de resistência e identidade como forma de visibilidade, mas também como um processo de ação mobilizadora e, desse modo, de constituir uma linguagem cultural e política. Assim, são concebíveis práticas sociais e culturais que avançam na produção de narrativas locais em um mundo de narrativas hegemônicas, do deslocamento da centralidade do discurso padrão para os interesses alternativos dos cidadãos periféricos, como também para os interesses dos mais diversos grupos étnicos, de gêneros, por todos aqueles que não se sentem contemplados na narrativa hegemônica. O sentido dialético da mobilização dos movimentos e coletivos periféricos ao denunciar as contradições vivas da realidade, oferece uma discussão do processo histórico e social com a interação ativa dos indivíduos por meio das práticas sociais e culturais realizadas nas quebradas, nos territórios da precariedade, onde estão concentradas as carências de equipamentos públicos e privados, fora, portanto, do quadrante sudoeste descrito por Flávio Villaça. Como abordei em outro $\operatorname{artigo}^{23}$,

Ainda que o entramado do espaço urbano seja percorrido por trajetórias que delineiam uma rede de circuitos sociais, persiste a estrutura física da cidade de muros, a exclusividade e o predomínio econômico de um setor associado à centralidade econômico-política denominado quadrante sudoeste.

A seguir, no propósito de descrever e consolidar este argumento, destaco a mobilização de alguns coletivos cuja atuação se dá no espaço urbano periférico, voltado para os grupos sociais em que aí convivem e habitam.

\subsection{Mulheres de Luta - Pretas Peri e Nós, Mulheres da Periferia}

As redes digitais propiciaram o surgimento de diversos coletivos compostos exclusivamente por mulheres, voltados para questões presentes no cotidiano
23. BIN, Marco A. Espaço urbano, performance e memória: a poética do corpo na poesia marginal e na cena cosplay. In: NUNES, Mônica Rebecca F. (org.). Cena Cosplay Comunicação, consumo, memória nas culturas juvenis. Porto Alegre: Ed. Sulina, 2015, pp. 77-111. 
feminino. Elas se organizam e se mobilizam na abordagem de diversos temas, do direito ao aborto aos preconceitos étnicos, das práticas culturais às ações políticas. Assim temos o grupos - Geledés; Mulheres na Luta; Nós, Mulheres da Periferia; dentre outros. Em uma breve aproximação das suas mobilizações diversificadas, é possível identificar o objeto das intervenções sociais.

A organização do coletivo Nós, Mulheres da Periferia ocorreu a partir de um artigo escrito por quatro das nove mulheres jornalistas que residem nas periferias de São Paulo e fazem parte do grupo. O artigo intitulado com o mesmo nome do coletivo, obteve grande repercussão, "encontrou eco entre nossas iguais, outras jovens ou não tão jovens mulheres moradoras da periferia de São Paulo que, finalmente, se sentiram representadas, lembradas e retratadas" ${ }^{24}$. A consolidação do projeto do coletivo se deu a partir de um conjunto de práticas políticas, visando principalmente,

- dar visibilidade aos direitos não atendidos das mulheres;

- problematizar os preconceitos e estereótipos limitadores que atravessam as questões de classe social, etnia e raça, muito presentes em razão da localização geográfica das residências das moradoras das bordas da cidade;

- contribuir para o empoderamento das mulheres moradoras da periferia de São Paulo, proporcionando a troca de conhecimento, de experiências e visibilidade sobre seus protagonismos, histórias e dilemas.

Em 2015, por intermédio do apoio do programa VAI (Valorização de Iniciativas Culturais), criado pela prefeitura de São Paulo, o coletivo realizou oficinas intituladas "Desconstruindo Estereótipos - eu, mulher da periferia na mídia", presentes em seis bairros das periferias (Perus, Campo Limpo, Guaianases, Jardim Romano, Jova Rural e Capão Redondo), ao longo de cinco meses. No total, as oficinas contaram com a presença de mais de cem mulheres de 17 a 93 anos, e, de acordo com o relato das entrevistadas:

Havia entre elas estudantes da rede pública (ensino regular ou EJA) e participantes de associações foram envolvidas no processo, em uma constante troca de conhecimentos e afetividade entre o coletivo e as mulheres. A dinâmica envolveu debates, exercícios, ensaios com máquinas fotográficas e telas de pintura. E, em um segundo ciclo do processo, nove destas mulheres foram entrevistadas individualmente, em vídeo, e de forma mais aprofundada. Os discursos, majoritariamente, refletem o desafio de enfrentar uma sociedade racista, machista e desigual, mas também a irreverência, força e os embates necessários para sobreviver neste ambiente.

As integrantes do coletivo destacam a importância das redes digitais como espaço para os debates e para a reflexão das suas propostas, com isso modificando o comportamento da mídia tradicional, que tomará "conhecimento de

24. Entrevista concedida pelo coletivo ao autor por e-mail em 19 out. 2016. histórias e pautas que antes ignoravam, [...] ampliando o repertório sobre o que é ser mulher no século 21 no país". 


\subsection{A força da poesia - Sarau da Cooperifa e Sarau do Grajaú}

A Cooperifa me proporcionou a primeira experiência com a realidade das periferias, e deve-se constatar o valor das relações comunais, sua força e sua importância justamente quando as vozes ainda se continham nas margens, sem direito a designar seus direitos, confinadas ao silêncio pela desigualdade atávica de nossa sociedade. Mas aos poucos, a Cooperifa passou a

exprimir a realização de sonhos, a possibilidade de crescimento individual e o anseio em produzir uma identidade coletiva, pautada na escritura e na declamação poética. A periferia torna-se [...] uma rede de reconhecimento, de pertencimento, de resistência ${ }^{25}$.

Uma das primeiras barreiras que o sarau da Cooperifa ultrapassou foi a de saltar os limites do Bar do Zé Batidão ${ }^{26}$ para chegar ao mundo, a partir do blog de seu poeta fundador e agitador cultural, Sérgio Vaz. Desse modo, os movimentos, antes conhecidos apenas pela comunidade do Jardim Guarujá e dos integrantes do sarau, tornaram-se universais. Não era mais necessário aguardar as noites de quarta-feira para saber o que tinha ocorrido, e o que ocorreria em termos de atividades culturais durante o resto da semana. O blog não só criou um contato inédito com os jovens poetas de outras periferias, restritos às suas quebradas, como os integrou pela palavra e pela ação. O sarau em si ficou como um evento a ser desfrutado antes e depois, com as imagens revelando as cores e a intensidade de cada encontro. Mais do que isso, ele permitiu um contato contínuo, onde se revelavam novos encontros fomentados pela poesia. Assim, era possível saber quem esteve presente, quem declamou, quem chorou, quem sorriu, quais as novidades e sobre declamações poéticas ocorridas fora do Batidão - nas escolas públicas, nas estações de metrô, nas bibliotecas. Aos poucos, outras redes sociais foram substituindo o blog, e hoje os contatos se dão primordialmente nas páginas do Facebook.

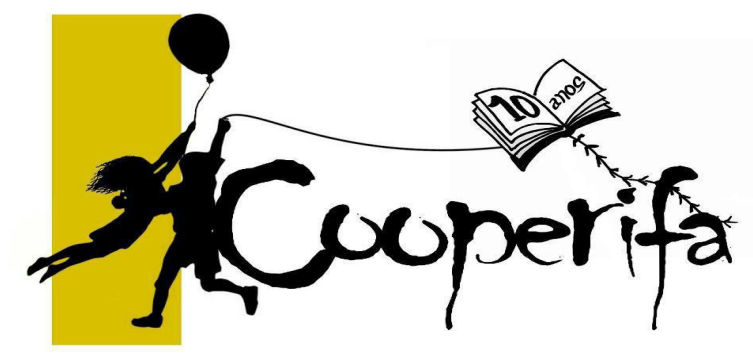

Figura 1: os signos que identificam a Cooperifa: crianças com o balão de ar e a pipa

O surgimento do sarau do Grajaú passou pelas mesmas etapas que definem o esforço pela constituição do espaço literário: o início em um local, a relocalização, o recomeço, a dedicação para mobilizar um público interessado. Segundo Daniel Brito, um dos integrantes do coletivo,
25. BIN, Marco Antonio. As redes de escrituras das periferias: a palavra como manifestação de cidadania. Tese de doutorado em Ciências Sociais. Programa de Estudos Pós-Graduados em Ciências Sociais, PUC-SP, 2009.

26. A poesia declamada nas periferias só é possível graças aos bares, um dos raros espaços públicos disponíveis. No caso da Cooperifa, ela ocorre no Bar do Zé Batidão; no do Grajaú, os encontros se dão no Bar do Havaí. 
27. Não confundir com 0 famigerado movimento de inspiração fascista $\mathrm{MBL}$, Movimento Brasil Livre.

28. Disponível em: <https:// redeextremosul.wordpress. com>. Acesso em: 20 jun. 2016.

29. Disponível em: <https:// vimeo.com/125173409/>. Acesso em: 20 jun. 2016.

30. Disponível em: <https:// vimeo.com/125054408> Acesso em: 20 jun. 2016.
O Sarau do Grajaú busca dar voz às pessoas que residem na periferia, e também deseja mostrar que para consumirmos cultura, não precisamos nos deslocar para as áreas centrais, pois, no bairro, residem diversas pessoas que fazem parte das mais variadas vertentes artísticas (artes cênicas, música, grafite, pintura, artes plásticas, poesia) e que podemos nos reunir para trocar ideias e construir a nossa própria história.

Os encontros presenciais promovem a troca de conhecimentos entre os participantes, um público predominantemente jovem, sempre no último sábado de cada mês, e a partir das redes digitais, há a divulgação dos eventos organizados e o registro fotográfico torna-se um aspecto importante, em toda a singeleza do gesto, pois "dessa forma, as pessoas que comparecem podem recordar, e as que não conhecem [o evento] podem ter uma ideia de como é o ambiente e, quem sabe, vir a conhecê-lo".

\subsection{A organização política - Rede de Comunidades do Extremo Sul de SP e MLB (Movimento de Luta nos Bairros, Vilas e Favelas) ${ }^{27}$}

O que me fez eleger, dentre tantas opções, a página de uma entidade das periferias vinculada à ação política, mas que encerrou suas atividades? Que fique bem explícito: encerraram-se as atividades em uma página individual, para juntar forças em com outros coletivos de luta em outro endereço virtual. Não obstante, a luta presencial prossegue lavrada cotidianamente, nas mesmas propostas de ação participativa. $\mathrm{O}$ sítio ${ }^{28}$ atualizava as mobilizações sociais de um assentamento que se transformou em bairro, o Jardim da União, não só com palavras, mas também com a produção de vídeos instrutivos da sua organização social. Assim, o coletivo construiu uma linguagem objetiva que coordenava o esforço de cada um na dura luta de cada dia. O vídeos produzidos são de extrema sensibilidade, em especial aquele que trata do trabalho de reciclagem ${ }^{29} \mathrm{e}$ outro que mostra a resistência da ocupação ${ }^{30}$ — não por acaso, os dois últimos do coletivo. Trata-se de um caso exemplar de uma comunidade constituída na ocupação da terra, ainda não reconhecida legalmente, que constrói um discurso para transmitir, internamente e para o mundo, suas formas de resistência civil. A criação de uma linguagem dialógica expõe a densidade de um drama agrário muito comum em nosso país, promovendo os desígnios de uma luta que não esmorece.

Abaixo, a declaração final do sítio digital, uma exortação à luta, à participação da comunidade com ousadia e esperança:

\section{Jardim da União resiste}

$O$ curto periodo em que foi suspenso o processo de reintegração de posse contra a ocupação do Jardim do União será marcado por muitas lutas e muitos esforços no sentido de combater a ameaça contra essa comunidade, que foi construída com tanta dedicação, com tanto companheirismo, OUSADIA e esperança. 
É com esse espírito que pedimos apoio à nossa Campanha "Jardim da União Resiste", para tornarmos conhecida a caminhada de seus tantos guerreiros e guerreiras, e para juntarmos força contra a violência do Estado.

Dentro dessa campanha, produziremos diversos vídeos que retratam diferentes dimensões dessa luta e da situação atual da ocupação. Pedimos a todos que se solidarizam com a Ocupação Jardim da União a nos ajudarem a difundir o vídeo abaixo e os outros materiais que iremos divulgar nas próximas semanas.

TODO PODER AO POVO! ${ }^{31}$

Já o MLB, Movimento de Luta nos Bairros, Vilas e Favelas, se organiza desde 1999, a princípio em Pernambuco e Minas Gerais, e logo se expande para outros 13 estados do país, promovendo seu papel social de ampliar o debate sobre a falta de moradias no país. Segundo o depoimento obtido junto ao movimento, a ideia de sua formação "foi resultado da necessidade de organizar lideranças comunitárias até então dispersas, num movimento que enfrentasse o fisiologismo existente no movimento comunitário e de bairro". ${ }^{32}$

O MLB tem como foco principal "a luta por moradia, o motor principal da luta pela reforma urbana, pois através dela conseguimos mobilizar milhares de pessoas, pressionar os governos e chamar a atenção para os problemas enfrentados pelo povo pobre nas grandes cidades". O movimento não está apenas organizado nas capitais dos estados em que atua, mas também em cidades de médio porte, como Mossoró (RN), Bayeux e Patos (PB), Jaboatão, Olinda e Caruaru (PE), Feira de Santana (BA), Nova Lima (MG), Diadema e São Bernardo (SP) e Duque de Caxias (RJ). Suas páginas nas redes digitais ${ }^{33}$ divulgam o cronograma de ocupações, as propostas de reforma urbana, a atuação em rede com outros coletivos e movimentos, como o Povo sem Medo, dentre outras informações. Segundo o depoimento por escrito, o papel desempenhado pelas redes digitais é relevante para a divulgação sobre a luta do movimento e, também, para ampliar a rede de ativistas, já que "muitas pessoas que hoje se organizam no MLB fizeram o primeiro contato conosco por meio dessas redes".

Também é possível o acesso da Rádio Popular ${ }^{34}$, onde em matéria gravada pode-se ouvir os depoimentos pessoais de coordenadoras mulheres do movimento, que com a graça de sua militância, constroem e organizam o processo de ocupação urbana em diversas cidades no país.

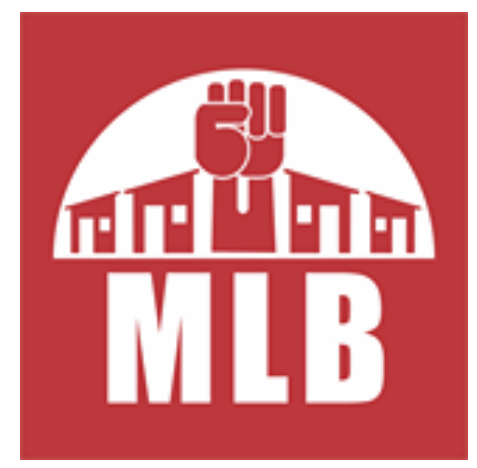

Figura 2: Logo do Movimento de Luta nos Bairros, Vilas e Favelas

31. Disponível em: $<$ https://redeextremosul. wordpress.com>. Acesso em: 5 mar. 2017.

32. Entrevista concedida pelo coletivo ao autor por e-mail em 22 ago. 2016.

33. O site <www.mlbbrasil.org>. Acesso em: 01 nov. 2016. Além da página no Facebook: <www. facebook.com/mlbrio>. Acesso em: 01 nov. 2016.

34. Disponível em: <www. mlbbrasil.org>. Acesso em: 5 mar. 2017. 


\section{ELEMENTOS PARA UMA CONCLUSÃO}

O exercício da democracia ganha o espaço digital ao oferecer o acesso ilimitado da comunicação. A tevê pública ganha o acesso nas telas dos netbooks ou dos Ipods; a rádio comunitária se reproduz nos tablets, levando a voz do cidadão que até pouco tempo era invisível. A ação política de um movimento social ou a atividade cultural de um coletivo informam e podem ser acompanhados nos sites desses grupos; fotos e vídeos podem ser capturados e compartilhados em distintas redes, como YouTube, Twitter, Facebook, Instagram; as convocatórias para eventos coletivos são acionadas por aplicativos de simples manejo como o WhatsApp. Com todas essas inovações tecnológicas, bem como seu acesso massivo, o alcance ideológico dos meios tradicionais de comunicação é limitado; a produção vertical e hierarquizada da informação perde sua força ${ }^{35}$.

A participação social nas mídias digitais propicia novas possibilidades à produção de informação, conhecimento e entretenimento. O tradicional conceito de comunidade definido pela vontade natural e espírito gregário, ganha novas roupagens ao imaginarmos as teias colaborativas tecidas no ciberespaço, estendendo os limites da comunicação e, conforme Henri Lefebvre, "é em seu relacionamento ativo com as realidades e por meio dele que o ser humano as penetra e captura o seu devir; o ser humano compreende as coisas ao transformá-la" ${ }^{36}$. É poderosamente instigante uma proposta como a do coletivo Nós, Mulheres da Periferia, que propõe tornar "as histórias e falas dessas mulheres (periféricas) ainda mais acessíveis e valorizadas”, ao abordá-las e discuti-las com as outras mulheres do mundo, ou a quem queira se interessar. $\mathrm{O}$ debate não se prende apenas ao universo das mulheres conhecidas, mas também inclui aquelas que serão conhecidas, todas tomadas pelos mesmos dilemas, pelas mesmas angústias, pelos mesmos desejos, na concepção de um mundo em contínua produção, "em via de enriquecimento e aprofundamento perpétuos" ${ }^{37}$. E esse é apenas um dos exemplos possíveis.

Com as alternativas múltiplas de participação e interação social, proporcionadas pelas redes constituídas pelas mídias digitais, o cidadão das periferias passa a dispor dos instrumentos para fazer ouvir sua voz tão ausente, mas também tão penetrada por desejos e questionamentos. Já não é preciso abandonar o território da precariedade para se colocar cada vez mais como protagonista e fugir do papel de figurante - ação indispensável para se pensar uma realidade social mais justa e participativa.

35. JENKINS, Henry, op. cit.

36. LEFEBVRE, Henri. Marxismo. Porto Alegre: LP\&M, 2009, p. 119.

37. Idem, p. 122.

\section{REFERÊNCIAS BIBLIOGRÁFICAS}

BIN, Marco Antonio. As redes de escrituras das periferias: a palavra como manifestação de cidadania. Tese de doutorado em Ciências Sociais. Programa de Estudos Pós-Graduados em Ciências Sociais, PUC-SP, 2009. 
- Espaço urbano, performance e memória: a poética do corpo na poesia marginal e na cena cosplay. In: NUNES, Mônica Rebecca F. (org.). Cena Cosplay - Comunicação, consumo, memória nas culturas juvenis. Porto Alegre: Ed. Sulina, 2015, pp.77-111.

CALDEIRA, Teresa. Cidade de Muros - Crime, segregação e cidadania em São Paulo. São Paulo: Editora 34/Edusp, 2000.

FREIRE, Paulo. Ação Cultural para a Liberdade. Rio de Janeiro: Editora Paz e Terra, 1979.

HOLSTON, James. Cidadania Insurgente - Disjunções da democracia e da modernidade no Brasil. São Paulo: Cia das Letras, 2013.

JENKINS, Henry. Cultura da Conexão. São Paulo: Editora Aleph, 2015.

KOWARICK, Lucio. Viver em Risco — sobre a vulnerabilidade socioeconômica e civil. São Paulo: Editora 34/Edusp, 2009.

LAPLANTINE, François. Aprender Antropologia. São Paulo: Editora Brasiliense, 2012.

LEFEBVRE, Henri. Marxismo. Porto Alegre: LP\&M, 2009.

MORDUCHOWICZ, Roxana. Los adolescentes y las redes sociales - la construcción de la identidade juvenil em Internet. Buenos Aires: Fondo de Cultura Económica, 2012.

MUNANGA, Kabengele. Negros e mestiços na obra de Nina Rodrigues. In: ALMEIDA, Adroaldo; SANTOS, Lyndon; FERRETTI, Sergio. Religião, Raça e Identidade. São Paulo: Ed. Paulinas, 2009, pp. 15-35.

VILLAÇA, Flávio. Espaço Intraurbano no Brasil. São Paulo: Estúdio Nobel/ Fapesp, 2001.

VIVEIROS, Eduardo. Equívocos da Identidade. In: GONDAR, Jo; DODEBEI, Vera. O que é Memória Social? Rio de Janeiro: Editora UFRJ, 2006, pp.145-160. 